\title{
CASO 14-2013: Masculino 32 años con Enfermedad de Still del Adulto y sordera neurosensorial
}

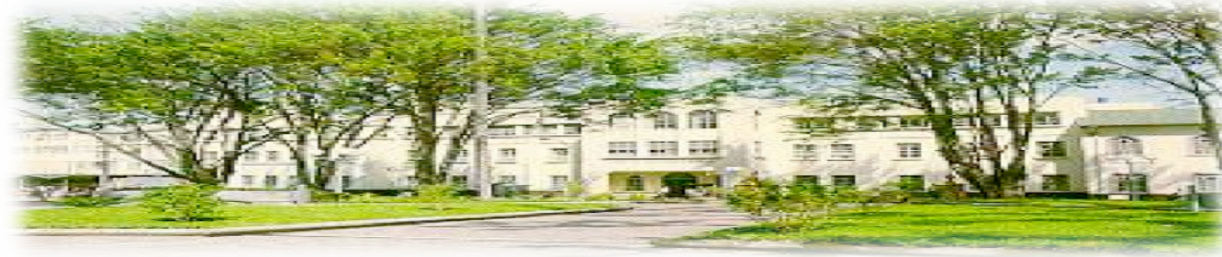

Hospital San Juan de Dias. San José. Costa Rica. Fundado en 1845

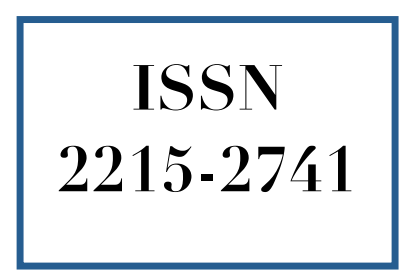

\section{Reporte de Caso}

Recibido:

Aceptado:
$25 / 07 / 2013$

$21 / 08 / 2013$
Marvin Sánchez Benavides ${ }^{1}$ Alexis Méndez Rodríguez ${ }^{2}$

\footnotetext{
${ }^{1}$ Médico Residente de Reumatología. Programa de Estudios de Posgrado UCR - CENDEISSS. Hospital Calderón Guardia. San José. Costa Rica. Correo electrónico: marsbcr@gmail.com

${ }^{2}$ Médico Especialista en Reumatología. Asistente del Servicio de Reumatología Hospital San Juan de Dios. Profesor de la Escuela de Medicina Universidad de Costa Rica. San José Costa Rica. Correo electrónico jamendezr@hotmail.com
}

\section{RESUMEN}

Masculino de 32 años, con antecedente de esteatosis hepática, quien consultó por cuadro de 4 meses de evolución de síntomas constitucionales, fiebre vespertina, disminución progresiva de la agudeza auditiva, asociado a elevación de reactantes de fase aguda, leucocitosis con neutrofilia, elevación de ferritina sérica y alteración de las pruebas de función hepática. Se documentó rash asalmonado evanescente en tronco. Se diagnosticó como Enfermedad de Still del Adulto. El presente caso discute la Enfermedad de Still del Adulto con sordera neurosensorial, de cuya asociación sólo se encuentra en un caso publicado en la literatura mundial.

\section{PALABRAS CLAVE}

Enfermedad de Still del Adulto. Sordera neurosensorial. Ferritina.

\section{ABSTRACT}

A 32 years-old man with a previous diagnosis of hepatic steatosis was admitted to an inpatient internal medicine hospital service, with a 4 months history of anorexia, fatigue, nocturnal fevers and progressive hearing loss, associated with neutrophilic leukocytosis, ferritin and acutephase reactants elevation, with liver enzyme abnormalities. The patient presented evanescent, salmon-colored rash on the trunk. A diagnosis of Adult Onset Still's Disease was made. Association of neurosensorial hearing lost with Adult Onset Still Disease is very rare, just one case published before.

\section{KEY WORDS}

Adult Onset Still's Disease. Neurosensory hearing lost. Ferritin. 


\section{CASO CLÍNICO}

Paciente masculino de 32 años, con antecedente de esteatosis hepática en control en el Servicio de Gastroenterología. Consultó por cuadro de 4 meses de evolución de sensación febril vespertina, cuantificada en $39{ }^{\circ} \mathrm{C}$, asociado a mialgias y artralgias ocasionales, disminución progresiva de la agudeza auditiva, no asociado síntomas respiratorios o digestivos. Dos semanas previas a dicha consulta presentó exacerbación de los síntomas clínicos descritos; asoció odinofagia y debilidad muscular generalizada. En el examen físico inicial se documentó adenopatías cervicales bilaterales, profundas, no móviles, duroelásticas y hepatomegalia de aproximadamente $2 \mathrm{~cm}$ BRCD. No lesiones en piel. El resto de la exploración física sin alteraciones evidentes.

Laboratorios iniciales evidenciaron elevación importante de VES y PCR; leucocitosis con neutrofilia, anemia normo-normo; discreta elevación de las pruebas de función hepática. Función renal y electrolitos normales. Ferritina sérica francamente elevada.

TC (Tomografía Computarizada) de sistema nervioso central reportada sin alteraciones. TC de tórax reportó mediastino con pequeñas adenopatías menores a $10 \mathrm{~mm}$, derrame pleural bilateral leve-moderado, con consolidación basal que presentaba broncograma aéreo. TC de abdomen demostró hepatomegalia sin focalizaciones, retroperitoneo con adenopatías menores a 10 $\mathrm{mm}$, con presencia de escaso liquido en fondo de saco posterior.

La audiometría reportó hipoacusia mixta (no se encontró el reporte formal).

El ultrasonido de abdomen reportó hepatomegalia leve con cambios reactivos en pared vesicular. Ultrasonido de tiroides evidenció nódulo de aspecto benigno en lóbulo tiroideo derecho.

El ecocardiograma transtorácico descartó la vegetaciones. Función sistólica y diastólica normales. La velocidad de conducción nerviosa y electromiografía se reportaron normales.

El aspirado de médula ósea evidenció hiperplasia granulocitica, de serie mieloide y megacariocitica. Fue negativa por infiltración neoplásica.
La gastroscopia demostró gastritis edematosa sin otras alteraciones. La broncoscopía con lavado broncoalveolar descartó lesión infiltrativa y las muestras por bacilos acido-alcohol resistentes fueron negativas.

Serología por VIH (Virus de Inmunodeficiencia Humana), VEB (Virus Epstein Barr), CMV (Citomegalovirus), VHB (Virus Hepatitis B) y VHC (Virus Hepatitis C) reportados como negativos.

Perfil inmunológico: ANA, Anticuerpo anticardiolipina, Factor Reumatoide, Anti PCC (péptido citrulinado cíclico), ANCA p y ANCA c reportados negativos. Niveles de complemento normales.

Ante los hallazgos clínicos y de laboratorio se planteó el diagnóstico de Enfermedad de Still del Adulto, en especial cuando se documentó un brote cutáneo asalmonado evanescente en tórax, relacionado con pico febril.

\section{Evolución clínica}

Se inició tratamiento con bolos de metilprednisolona por tres días, seguido de esteroides VO, con disminución de leucocitosis, disminución de los reactantes de fase aguda, disminución en las pruebas de función hepática, hay caída de la fiebre, mejoría de síntomas constitucionales, incluyendo mejoría paulatina de la hipoacusia. El paciente es egresado en excelente estado general con diagnóstico de Enfermedad de Still del Adulto.

El control posterior en Consulta Externa de Reumatología evidenció normalización de los reactantes de fase aguda, hemograma y de la audiometría, que reportó recuperación prácticamente completa (Figura1).

\section{DISCUSIÓN}

La Enfermedad de Still del Adulto es un desorden inflamatorio de etiología desconocida, caracterizado por picos febriles vespertinos, artralgias y rash evanescente en tórax, que constituye uno de los principales diagnósticos de exclusión en pacientes con fiebre de origen oscuro ${ }^{(1,3)}$. Debe su nombre a George Still, quien publicó una serie de 22 casos en niños en $1897^{(1,4)}$, es a partir de 
1971 que se introduce la Enfermedad de Still del Adulto como una nueva entidad clínica ${ }^{(1)}$.

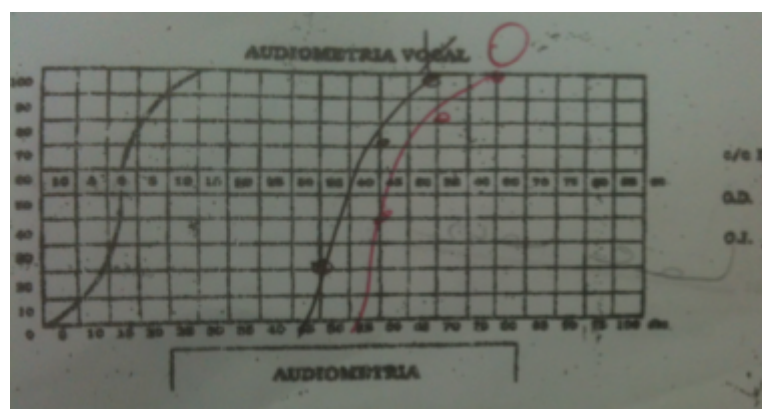

Figura 1. Audiometría realizada en la consulta externa, con recuperación prácticamente completa.

Fuente revisión del expediente

La etiología es hasta la fecha desconocida, algunas series de casos han demostrado cierta relación con algunos HLA, especialmente HLA-B17, HLA-B18, HLA-B35, no obstante estos hallazgos no han podido ser reproducidos ${ }^{(1)}$. Algunos estudios han propuesto agentes infecciosos como detonantes del proceso inmunológico, con base en mimetismo molecular, pero los resultados no son concluyentes ${ }^{(1)}$. En los últimos años varios estudios han evidenciado una alteración en la producción de citoquinas, en especial las relacionadas con el Linfocito Th1, debido a observaciones comparativas contra grupos control ${ }^{(1,4)}$.

Desde el punto de vista clínico la Enfermedad de Still del Adulto se caracteriza por una triada conformada por fiebre de predominio vespertino, artralgias/artritis y rash evanescente ${ }^{(1-6)}$. La fiebre se caracteriza por ser vespertina, usualmente superior a los $39^{\circ} \mathrm{C}$ y es concomitante con empeoramiento de los síntomas constitucionales y aparece de forma simultánea con el rash evanescente. Dicho rash se describe como asalmonado, predomina en áreas proximales de tórax y miembros superiores, respeta cara y áreas distales.

Los estudios histológicos evidencian inflamación perivascular e incluso por inmunohistoquimica se reporta el depósito de complejos inmunes y complemento $^{(1)}$. La artritis suele ser simétrica, poliarticular y afecta principalmente rodillas, tobillos, así como muñecas, hombros y pequeñas articulaciones de manos ${ }^{(1,3-5)}$. Otros hallazgos frecuentes incluyen las mialgias, serositis, hepa- toesplenomegalia y linfadenopatías ${ }^{(1,2)}$. La presencia de lesión renal caracterizada por glomerulonefritis colapsante, amiloidosis, así como la neuropatía craneal y meningitis aséptica se han descrito en algunas series de $\operatorname{casos}^{(1)}$. Es frecuente la elevación de las pruebas de función hepática que se considera secundario al uso inicial de antiinflamatorios no esteroidales ${ }^{(1,2)}$.

En relación a los laboratorios, en frecuente encontrar en el hemograma leucocitosis a expensas de neutrofilia, anemia normocítica normocrómica y trombocitosis ${ }^{(1-6)}$. En tres cuartas partes de los pacientes se advierte elevación importante de los reactantes de fase aguda, así como de las pruebas de función hepática. Un hallazgo característico de la enfermedad lo constituye la elevación importante de la ferritina sérica hasta valores cinco veces sobre el corte superior, que sin embargo no constituye una prueba de alta especificidad para el diagnóstico ${ }^{(1-3)}$. Actualmente se da mayor valor diagnoóstico a la fracción glicosilada de la ferritina, la que característicamente disminuye hasta menos del $20 \%$ de su valor basal en la Enfermedad de Still del Adulto, con una especificidad del $93 \%{ }^{(1,5)}$. Los estudios inmunológicos son normales incluyendo ANA, FR y Anti PCC ${ }^{(1,4)}$. Los estudios radiológicos son de poca ayuda en estadios iniciales, no obstante estudios japoneses han encontrado una relación entre la disminución del espacio articular a nivel del carpo con una mayor probabilidad de cronicidad y de anquilosis articular a ese nivel ${ }^{(1)}$.

El diagnóstico de la Enfermedad de Still del Adulto es de exclusión, en virtud de los hallazgos clínicos, apoyados en los exámenes de laboratorio. Actualmente se cuenta con algunas escalas de clasificación, entre ellas los criterios de Yamaguchi son los que tienen una mayor sensibilidad $^{(1,4,5)}$ (Cuadro 1).

Con relación al pronóstico, la enfermedad presenta tres cursos diferentes: autolimitado o monocíclico, intermitente o policíclico y un patrón articular crónico, siendo esta última la que se asocia con mayor posibilidad de morbilidad, en especial por destrucción articular importante con necesidad de reemplazos articulares ${ }^{(1,5)}$.

En cuanto al tratamiento, los fármacos con más evidencia clínica son los AINEs, los esteroides y los modificadores de enfermedad reumática, 
siendo los dos primeros los más utilizados y considerados la primer línea de tratamiento ${ }^{(1,3,4)}$. Algunas series han demostrado la eficacia de terapias tales como gammaglobulina y los fármacos biológicos, en especial en casos refractarios a la terapia convencional ${ }^{(1,3)}$.

Cuadro 1. Criterios diagnósticos de la Enfermedad de Still del Adulto.

\section{Criterios de Yamaguchi}

Criterios mayores

- Artralgia $>2$ semanas.

- Fiebre $>39$ C, intermitente, $>1$ semana.

- Rash típico.

- Leucocitosis $>10,000$ ( $>80 \%$ granulocitos). Criterios menores

- Odinofagia.

- Linfadenopatía y/o esplenomegalia.

- $\quad$ Alteración en pruebas de función hepática.

- Factor reumatoide y ANA negativos.

Exclusión de otros diagnósticos

- Infecciones.

- Malignidad.

- Otras enfermedades reumatológicas.

Diagnóstico con 5 criterios, al menos 2 criterios mayores.

\section{Criterios de Fautre}

Criterios mayores

- $\quad$ Fiebre en picos $>39$ C.

- Artralgia.

- Eritema transitorio.

- Faringitis.

- Granulocitos $>80 \%$

- Ferritina glicosilada $<20 \%$

Criterios menores

- Rash maculopapular.

- $\quad$ Leucocitos $>10,000$.

Diagnóstico con 4 criterios mayores o 3 criterios mayores y 2 menores.

Fuente: modificado de 1,4 y 5

En nuestro reporte, el paciente presentó los hallazgos clínicos típicos, las alteraciones en los laboratorios descritos en la literatura, así mismo cumplió con los criterios diagnósticos actuales.

La hipoacusia en el contexto de enfermedad sistémica debe de hacer considerar patologías tales como Granulomatosis de Wegener, Policondritis recurrente, Poliarteritis nodosa y Lupus eritematoso sistémico entre otras, las cuales se descartaron tanto desde el punto de vista clínico como con laboratorios correspondientes ${ }^{(6)}$.

La revisión bibliográfica presenta solo un caso en los que la hipoacusia fue uno de los síntomas iniciales de la Enfermedad de Still del Adulto, reportado en la literatura en el año $1988^{(6)}$.

\section{CONCLUSIONES}

La enfermedad de Still del adulto es una entidad rara, de etiología no clara, donde se propone un desencadenante posiblemente infeccioso, aún no determinado.

El diagnóstico de la entidad es básicamente de exclusión, sin embargo hay criterios diagnósticos específicos a tomar en cuenta, sobre todo cuando otras patologías de estirpe reumatológico han sido descartadas.

La sordera neurosensorial como manifestación clínica al momento de la presentación es poco frecuente, por lo que el presente caso reviste mayor importancia, tomando en cuenta la evolución y buena respuesta de dicha sordera al tratamiento específico, demostrado por la audiometría.

\section{BIBLIOGRAFÍA}

1. Efthimiou P Paik PK Bielory L. Diagnosis and management of adult onset Still disease. Ann Rheum Dis 2006;65:564-572.

2. Knockaert D. Recurrent Fevers of Unknown Origin. Infect Dis Clin N Am 2007;21: 1189-1211.

3. Zenone T. Fever of Unknown Origin in Rheumatic Diseases. Infect Dis Clin N Am 2007;21:1115-1135.

4. Wung P Pipeling M Wigley F. "Still" ill?. The American Journal of Medicine, 2008;121(6):491-493.

5. Aggarwal N Szostek J. 52-Year-Old Man With Arthralgias, Fever, and Fatigue. Mayo Clin Proc Jun 2010;85(6):568-571.

6. Markusse H Stolk B Van Der Mey A De Jonge-Bok J Heering K. Sensorineural hearing loss in adult onset Still's disease. Annals 
of the Rheumatic Diseases, 1988;47:600-

602 . 